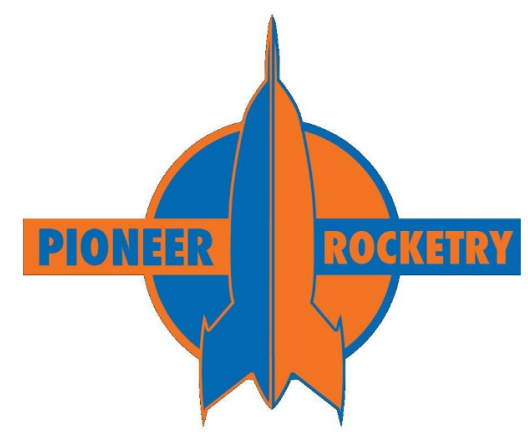

\title{
Pioneer Rocketry 2019 Midwest High-Power Rocket Competition
}

\author{
Zach Geier, Erin Kammann, Brian Lee, Nathaniel Michek, Robert Underwood, and Nathaniel \\ Zabel \\ (Pioneer Rocketry, University of Wisconsin-Platteville) \\ Platteville, WI, USA
}

\begin{abstract}
The Minnesota Space Grant Consortium hosts the Midwest High-Power Rocket Competition every year. This year the competition involved efficient supersonic flight. Each team needed to design a rocket that would undergo two flights. The first launch was on a competition provided motor with the goal of maximizing velocity and altitude. The second launch was on a team selected motor, with the goal of reaching supersonic flight on the lowest impulse motor possible. A custom sensor suite was required, and additional points were awarded for including custom telemetry. Pioneer Rocketry's rocket this year, Man That Thing's Tiny (MT3), was designed to be as small as possible while being stable and safe. Flying a minimum diameter rocket presented many challenges that prompted the team to make several unorthodox design choices. At the competition launch, MT3's first flight was very close to the simulation. Unfortunately, the rocket was not recovered after the second flight.
\end{abstract}

\section{Introduction}

The Midwest Rocket Launch (MRL) competition is held annually by the Minnesota Space Grant Consortium each May. Due to rain this year, the competition flights were rescheduled to a July 6th Launch at Bong State Recreation Area. The 2019 MRL competition involved efficient supersonic flight. Teams from across the Midwest, the United States, and from Egypt attempted to design and fly an efficient supersonic rocket. Two flights were required, once on a standardized competition motor, and once on a team-selected motor.

\section{Rocket Operation Assessment}

2.1 General rocket design Based on the competition guidelines the rocket had to fall within a few general limits. At a minimum the rocket had to be $54 \mathrm{~mm}$ in diameter. Additionally the stability had to fall between 1 and 3 cal. Due to these constraints, and the team's goal of reducing the rocket's size to improve performance on lower impulse motors, MT3 was a 27.5 inch tall rocket with three fins that allowed for the stability to fall within the limits and have enough room for electronic systems. 


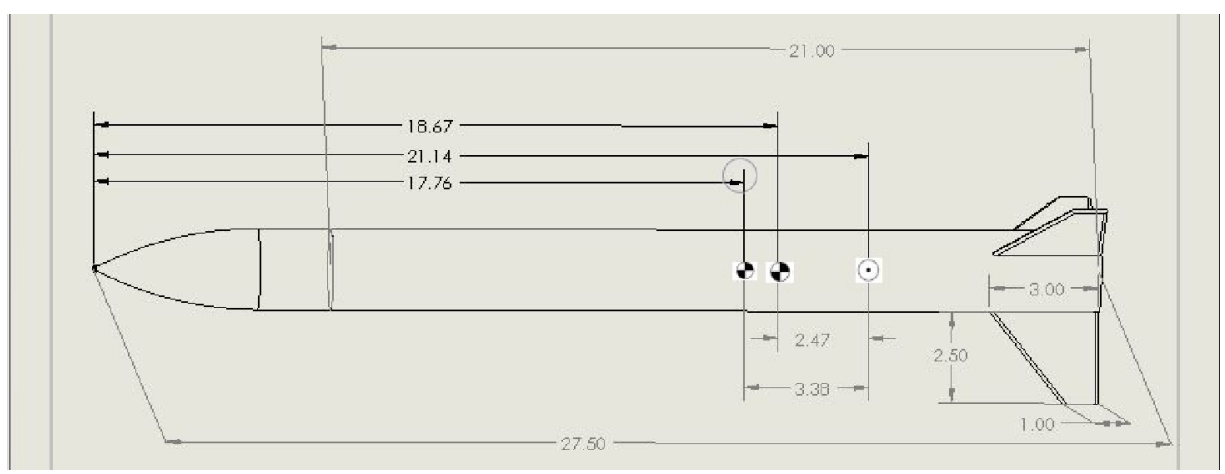

2.2 Propulsion system specifications The first competition launch was required to be on the I218-WT, while the second launch would be on a motor selected by the team. When selecting the second motor, the team initially set a goal of using the same motor on both flights. This would mean designing a rocket to achieve supersonic flight on the I218-WT. This was seen as ideal, since it would give a high velocity on the first flight and be a low impulse motor for the second flight. When this proved not to be feasible, the team simulated the rocket on every possible I and J class motor and entered the simulation data into a custom spreadsheet that graded the rocket's flight performance on each motor using the scoring equation provided by the competition.

$$
F M=\frac{\text { Impulse } \times \text { maximum thrust } \times \text { maximum altitude }}{1.0 \times 10^{9}}(1) .
$$

From this process, the 1287-SS was selected as the optimal motor to push MT3 to a supersonic velocity at the lowest impulse.

2.3 Flight trajectory assessment Flight data was only recovered from the first flight, as the rocket was not recovered after the second flight. As can be seen in Figure 1 and Figure 2, weathercocking, a change in flight trajectory due to forces created on the fins from wind, did occur. Weathercocking was observed in previous test flights and was expected if winds were above 10 $\mathrm{mph}$. A second problem from previous flights was a corkscrew effect created by a slightly canted fin. In one of the test flights there was a significant angle of attack due to these problems. Based on photos and videos from the competition flight MT3 did not launch with a corkscrew effect, as the rocket was rebuilt with the canted fin properly aligned prior to the competition launch. 


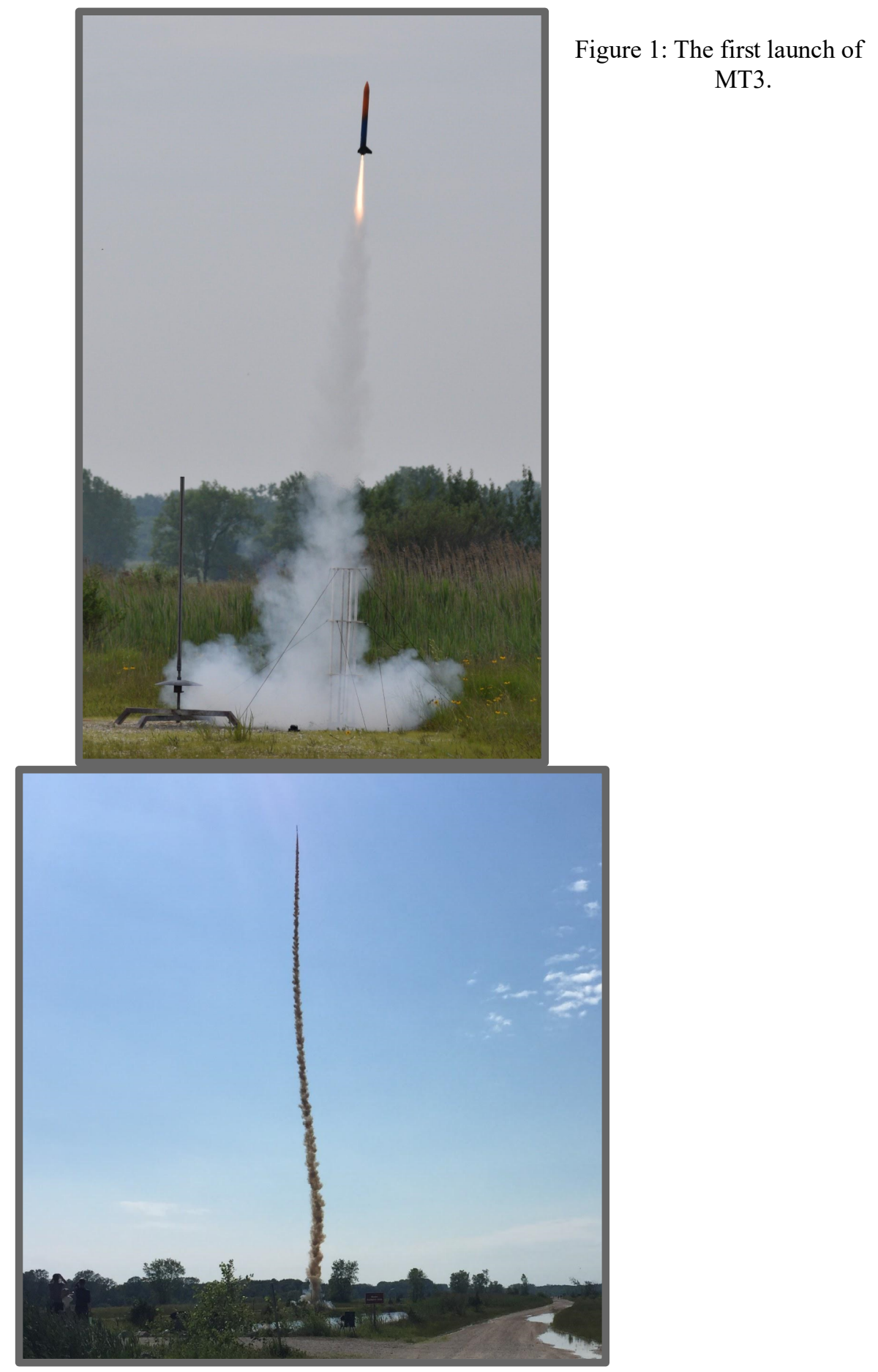

Figure 2: MT3's second launch.

2.4 Recovery system assessment Due to the payload taking up the entire front section of MT3, a rear deploy, dual event recovery scheme was implemented. This included a 5 in drogue parachute that came out at apogee with a 30 in main parachute restricted with a Jolly Logic Chute 
Release until $700 \mathrm{ft}$. This allowed the rocket to descend rapidly at $132 \mathrm{ft} / \mathrm{s}$ for shorter recovery time, before having a final landing speed of $21 \mathrm{ft} / \mathrm{s}$. This worked very well, as the first flight of MT3 landed within three hundred yards of the launch site.

2.5 Ground recovery assessment MT3 was successfully recovered after its first flight, as shown in Figure 3, but was unfortunately lost after the required second flight due to a fault in the radio tracker and loss of communication with the on-board GPS system.

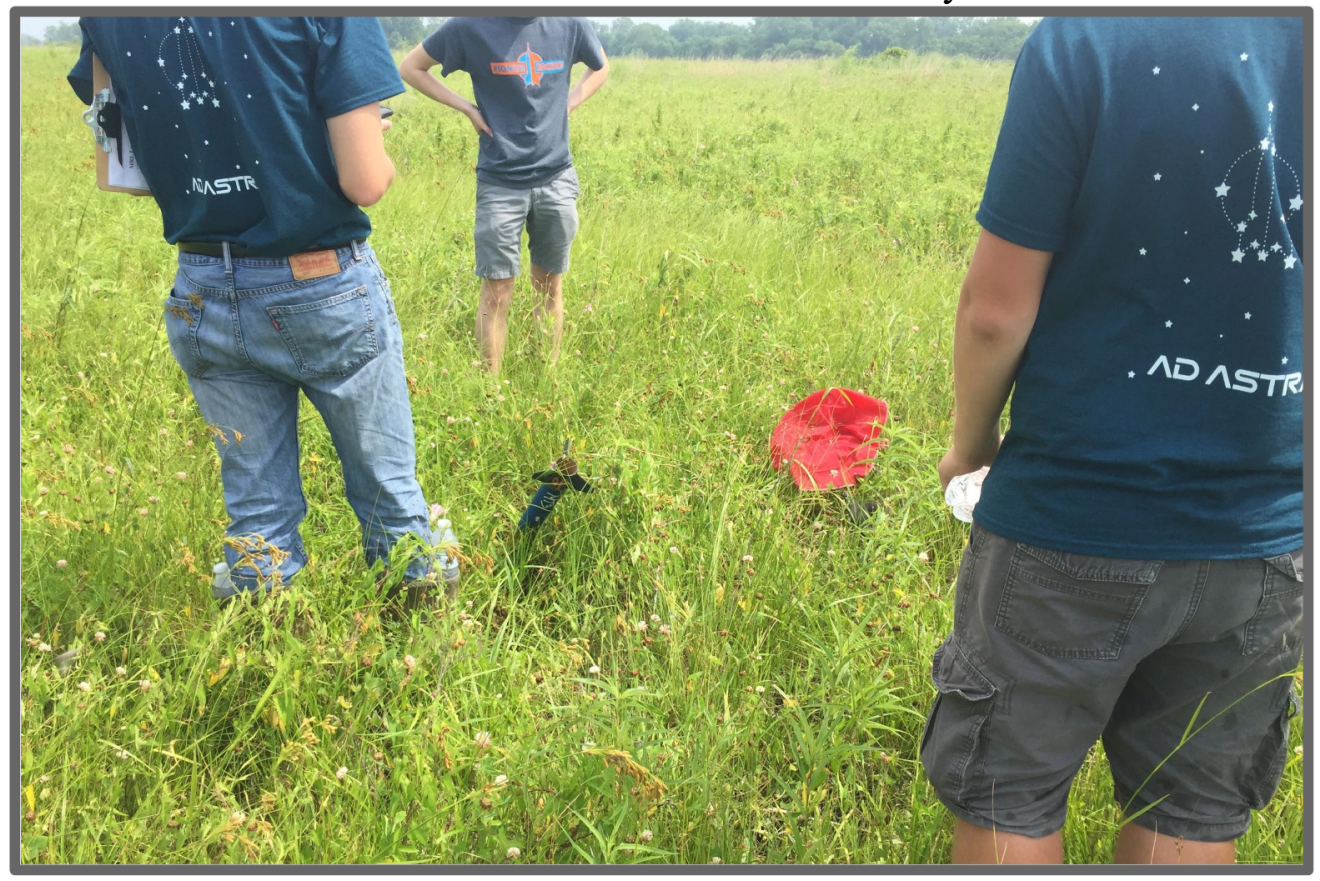

Figure 3: Recovery of MT3 after first flight. 
2.6 Assessment of custom electronics MT3 included a custom sensor suite and radio telemetry system. The custom sensor suite included a gyroscope, barometer, accelerometer, and a pair of Adafruit 32u4 microcontrollers. From the sensors; axial acceleration, altitude, and roll could be recorded at a rate of $10 \mathrm{HZ}$. A pair of LoRa radios, one in the avionics bay of MT3, and one on the ground, were included for radio communication. A GPS module was to be used to track the rocket's location. Once MT3 launched, the sensor suite would log flight data. Five seconds after apogee was detected, the radio would begin to transmit the logged sensor data to the ground station, then transmit the GPS data. Unfortunately, the micro-SD was not retrieved after the initial flight, and as the rocket was not recovered after the second flight, no data from the custom sensor suite was recovered. No data was transmitted between the rocket and ground, as the radios were outside of range.

2.7 Pre and post launch procedure assessment There was a delay of 4 hours for the first launch due to rain and low cloud ceiling. This delay restricted the time available for launching and recovery of MT3. The team was still able to accomplish both flights safely due to the implementation of pre-flight checklists that were developed and streamlined over several test launches.

\section{Discussion of Results}

3.1 Altimeter data analysis MT3 was modeled in OpenRocket and simulations were run to predict its flight performance. During the construction process the team continually updated the model to accurately reflect the masses of all included components. The simulation predicted an altitude of $6665 \mathrm{ft}$, while MT3's first competition flight reached $6980 \mathrm{ft}$ as shown in Table 1. Additionally, Figure 4 shows that apogee occurred approximately 18 seconds into launch.

\begin{tabular}{|c|c|c|c|}
\hline \multicolumn{4}{|c|}{ Raven 4 Data } \\
\hline Flight 1 & $\begin{array}{c}\text { Max altitude } \\
\text { (ft) }\end{array}$ & $\begin{array}{c}\text { Max velocity } \\
\text { (Mach) }\end{array}$ & $\begin{array}{c}\text { Max acceleration } \\
(\mathrm{G})\end{array}$ \\
\hline I-218 & 6980 & 0.95 & 22.18 \\
\hline & & & \\
\hline Flight 2 & $\begin{array}{c}\text { Max altitude } \\
(\mathrm{ft})\end{array}$ & $\begin{array}{c}\text { Max velocity } \\
\text { (Mach) }\end{array}$ & $\begin{array}{c}\text { Max acceleration } \\
(\mathrm{G})\end{array}$ \\
\hline
\end{tabular}




\begin{tabular}{|c|c|c|c|}
\hline I-287 & NA & NA & NA \\
\hline \multicolumn{3}{|c|}{ OpenRocket } \\
\hline Motor & $\begin{array}{c}\text { Max altitude } \\
(\mathrm{ft})\end{array}$ & $\begin{array}{c}\text { Max velocity } \\
\text { (Mach) }\end{array}$ & $\begin{array}{c}\text { Max acceleration } \\
(\mathrm{G})\end{array}$ \\
\hline I-218 & 6665 & 0.94 & 19.6 \\
\hline I-287 & 6491 & 1.04 & 27.5 \\
\hline
\end{tabular}

Table 1: Table of flight characteristics

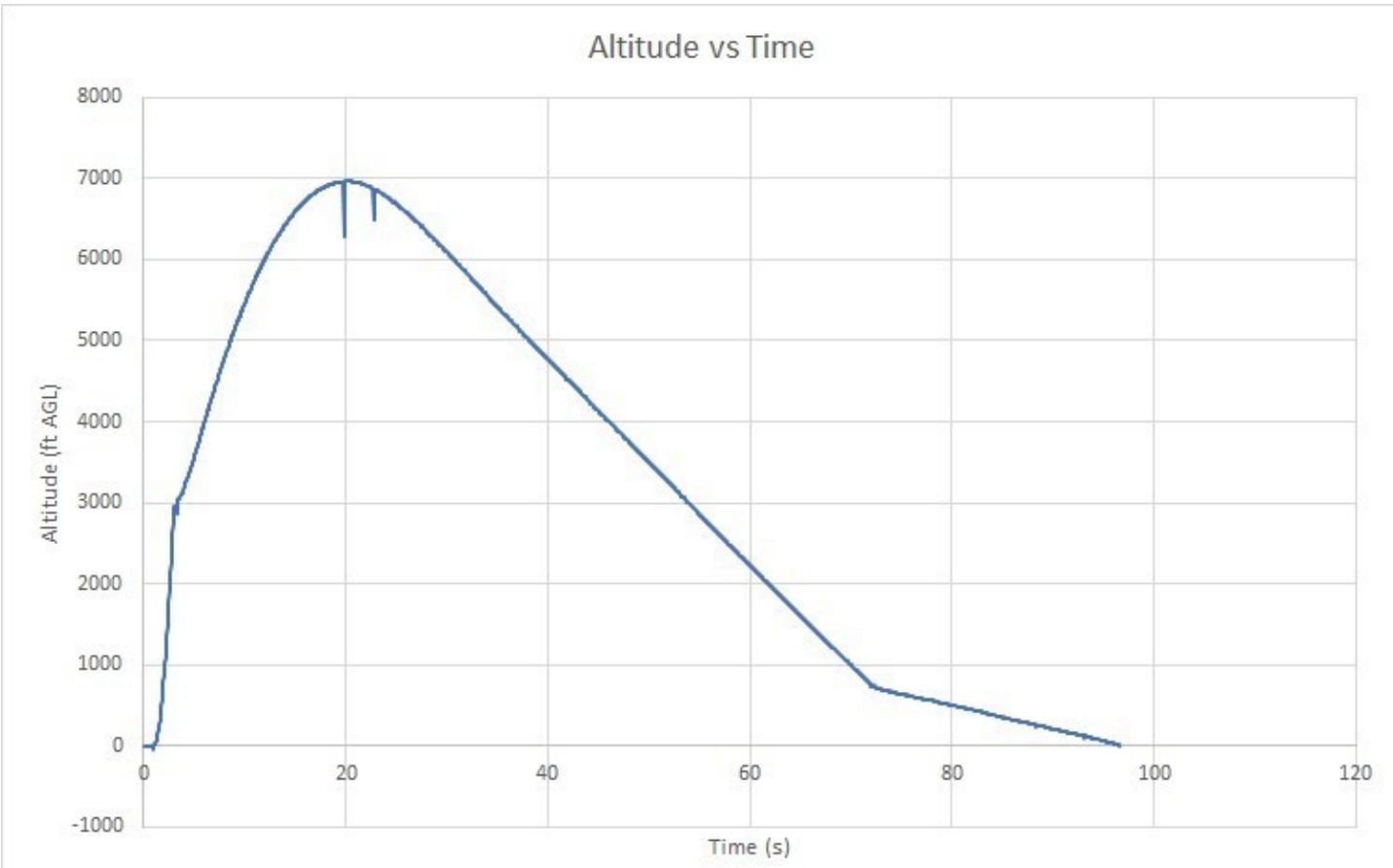

Figure 4: The Raven 4 graph of the first flight of MT3. 


\section{Conclusion}

The MRL team was very pleased to be able to fly their rocket for the competition even after the scheduled competition flights were cancelled due to rain. After a successful first flight the team was excited and optimistic for the second flight with the attempt to pass the speed of sound. After the first flight, a couple of small modifications were needed due to the unfortunate event of landing in water. With the unsuccessful recovery of the second flight the team is disappointed to state that there is no way of knowing whether MT3 made it supersonic.

Pioneer Rocketry is thankful to have the opportunity to participate in this competition year after year. The new members that have participated this year are eager to see what following years have in store for them. Each year, the team gains new knowledge about rockets and have a blast working together. Pioneer Rocketry is thrilled to have this opportunity to share their enthusiasm for aerospace with the world.

\section{Acknowledgements}

Pioneer Rocketry thanks the Minnesota Space Grant Consortium for running and hosting the competition and the Wisconsin Space Grant Consortium for funding for this competition. Additionally, Pioneer Rocketry thanks Jake Ellenberger, our high-power mentor, and Katie Rabidoux for the helpful suggestions throughout all stages of the competition. We would like to thank Tim Lehr and Gary Stroick to for all of the assistance they have provided. We would like to thank the University of Wisconsin-Platteville and Packaging Corporation of America for financial assistance provided to the club. Finally, we thank UW-Platteville Pioneer Farms for a suitable location for launch tests. 